Optical spectroscopy of oxygen precipitates in heavily doped p-type silicon

This content has been downloaded from IOPscience. Please scroll down to see the full text. 2002 J. Phys.: Condens. Matter 1413185

(http://iopscience.iop.org/0953-8984/14/48/367)

View the table of contents for this issue, or go to the journal homepage for more

Download details:

IP Address: 146.175.11.111

This content was downloaded on 10/12/2013 at 09:39

Please note that terms and conditions apply. 


\title{
Optical spectroscopy of oxygen precipitates in heavily doped p-type silicon
}

\author{
E Simoen ${ }^{1}$, R Loo ${ }^{1}$, C Claeys ${ }^{1,2}$, O De Gryse ${ }^{3}$, P Clauws $^{3}$, J Van Landuyt ${ }^{4}$ \\ and $O$ Lebedev $^{4}$ \\ ${ }^{1}$ IMEC, Kapeldreef 75, B-3001 Leuven, Belgium \\ ${ }^{2}$ E E Department, KU Leuven, Kasteelpark Arenberg 10, B-3001 Leuven, Belgium \\ ${ }^{3}$ Department of Solid-State Sciences, Ghent University, Krijgslaan 281 S1, \\ B-9000 Gent, Belgium \\ ${ }^{4}$ RUCA-EMAT, Groenenborgerlaan 171, B-2020 Antwerpen, Belgium \\ E-mail: Cor.Claeys@imec.be
}

Received 27 September 2002

Published 22 November 2002

Online at stacks.iop.org/JPhysCM/14/13185

\begin{abstract}
Results are presented on the photoluminescence (PL) characterization of heavily doped $\mathrm{p}^{+}$Czochralski silicon, which has been subjected to a two-step, oxygen precipitation heat treatment. It will be shown that the presence of oxygen precipitates gives rise to the D1, D2 and D5 lines, where the energy of the D1 line shifts to lower values for a stronger degree of precipitation. The occurrence of these PL features is also a function of the boron concentration in the $\mathrm{p}^{+}$material. The PL results are compared with Fourier transform infrared absorption data and with transmission electron microscopy results. From this, it is concluded that PL has a good potential for use in the assessment of oxygen precipitation in heavily doped silicon.
\end{abstract}

(Some figures in this article are in colour only in the electronic version)

\section{Introduction}

Currently, there is a strong drive to use epitaxial ('epi' -) silicon wafers in the volume production of advanced microelectronic circuits. Epilayers on both heavily $\left(\mathrm{p}^{+}\right)$and lightly doped $\left(\mathrm{p}^{-}\right)$substrates yield high-quality wafers, which are able to meet the ever tighter material requirements of the 'SIA roadmap' [1]. One of the major advantages of epi-material is the absence of so-called crystal-originated particles (COPs), occurring in pulled Czochralski (Cz) silicon, which consist of large vacancy clusters formed during the cooling of the crystal from the melt temperature. These COPs have a strong impact on the gate oxide integrity (GOI) of MOS devices and can also enhance the junction leakage current, when they exist in the vicinity of the depletion region [2]. 
Table 1. Description of the epi-samples used in the study. The epilayer thickness was $3 \mu \mathrm{m}$. A1 refers to a single $\mathrm{HT}$ at $700{ }^{\circ} \mathrm{C}$, while A2 refers to a two-step treatment.

\begin{tabular}{llll}
\hline Label & Resistivity $(\mathrm{m} \Omega \mathrm{cm})$ & Doping density $\left(\mathrm{cm}^{-3}\right)$ & Heat treatment \\
\hline B3-A1 & 19 & $3.7 \times 10^{18}$ & $700^{\circ} \mathrm{C} / 50 \mathrm{~h}$ \\
B6-A1 & 10.1 & $9.1 \times 10^{18}$ & $700^{\circ} \mathrm{C} / 24 \mathrm{~h}$ \\
B3-A2 & 19 & $3.7 \times 10^{18}$ & $700^{\circ} \mathrm{C} / 32 \mathrm{~h}+900^{\circ} \mathrm{C} / 16 \mathrm{~h}$ \\
B6-A2 & 10.1 & $9.1 \times 10^{18}$ & $700^{\circ} \mathrm{C} / 32 \mathrm{~h}+900^{\circ} \mathrm{C} / 16 \mathrm{~h}$ \\
B12-A2 & 68 & $4.8 \times 10^{17}$ & $700^{\circ} \mathrm{C} / 32 \mathrm{~h}+900^{\circ} \mathrm{C} / 16 \mathrm{~h}$ \\
B14-A2 & 200 & $1.0 \times 10^{17}$ & $700^{\circ} \mathrm{C} / 32 \mathrm{~h}+900^{\circ} \mathrm{C} / 16 \mathrm{~h}$ \\
\hline
\end{tabular}

It is well established that the oxygen precipitate density in heat-treated $\mathrm{Cz}$ silicon is increased by heavy boron doping [3]. This enhances the internal gettering capability of $\mathrm{p} / \mathrm{p}^{+}$epi-material. Key to the understanding of the oxygen precipitation behaviour is the assessment of the interstitial oxygen concentration, denoted by $\left[\mathrm{O}_{\mathrm{i}}\right]$, and the amount of oxygen in $\mathrm{SiO}_{x}$ precipitates, which requires a dedicated analysis, based on infrared absorption spectroscopy $[4,5]$.

One route to gaining information on precipitated oxygen is by investigating the absorption peaks around $1100 \mathrm{~cm}^{-1}$ at $300 \mathrm{~K}$ [6]. For heavily doped $\mathrm{p}^{+}$silicon this is possible by irradiating the sample with a high fluence $\left((1-3) \times 10^{19} \mathrm{~cm}^{-2}\right)$ of $2 \mathrm{MeV}$ electrons at room temperature [4]. In this way, the material becomes transparent in the mid-infrared region due to a deactivation of the B dopant atoms, through the creation of radiation damage. Alternatively, it has recently been demonstrated that the study of the well-known D1-D2 photoluminescence (PL) lines [7] in heat-treated $\mathrm{Cz}$ silicon could provide further insight into oxygen precipitation [8, 9]. It has in fact been shown that the line position (energy) depends sensitively on the details of the oxygen precipitation treatment $[8,9]$.

Therefore, it is the aim of this work to investigate by means of PL the oxygen precipitation behaviour in heavily doped $\mathrm{p}^{+}$silicon. Materials with different starting resistivities have been used for that purpose. If successful, this would allow study of the optical properties of oxygen precipitates in $\mathrm{p}^{+}$silicon without the need for heavy electron irradiation. One complicating factor when dealing with heavily doped material is the associated band-gap narrowing, which causes a shift and a broadening of the PL lines of excitons bound to the dopants [10-12]. The results of this initial PL study will be compared with Fourier transform infrared (FTIR) data obtained on thinned and/or electron-irradiated samples. The former method yields $\left[\mathrm{O}_{\mathrm{i}}\right]$ and $\Delta\left[\mathrm{O}_{\mathrm{i}}\right]$ (the concentration of precipitated oxygen after heat treatment $(\mathrm{HT})$ ), while the latter provides information on the presence of $\mathrm{SiO}_{x}$ precipitates $(1<x<2)$ [4]. Structural defects have been characterized by transmission electron microscopy (TEM).

\section{Experimental details}

$\mathrm{p}^{+}$silicon wafers with a $3 \mu \mathrm{m}$ thick epilayer and four different resistivities, ranging from 10.1 to $200 \mathrm{~m} \Omega \mathrm{cm}$, have been heat treated. The relevant electrical parameters of the starting material are summarized in table 1 . The samples received different HTs, as described in table 1 . As there was no trace of precipitate bands for the $\mathrm{B} 3$ and $\mathrm{B} 6$ material after a $700{ }^{\circ} \mathrm{C}$ anneal only, a second set of samples was prepared, which underwent a two-step HT, consisting of $32 \mathrm{~h}$ at $700^{\circ} \mathrm{C}$ and $16 \mathrm{~h}$ at $900^{\circ} \mathrm{C}$ under Ar flow. Results corresponding to the single-and double-anneal treatments are labelled $\mathrm{A} 1$ and $\mathrm{A} 2$, respectively.

For the PL measurements, the samples were mounted in a liquid helium cryostat. Excitation by a $488 \mathrm{~nm}$ Ar laser was utilized. Different excitation power densities $P$ ranging from 5 to $50 \mathrm{~mW} \mathrm{~mm}^{-2}$ were applied. 
Table 2. Peak energy for the main PL lines in the $\mathrm{p}^{+}$epi-material, before and after HT $\left(50 \mathrm{~mW} \mathrm{~mm}{ }^{-2} ; T=5.5 \mathrm{~K}\right)$. A1: a single $\mathrm{HT}$ at $700^{\circ} \mathrm{C}$, A2: two-step HT $700^{\circ} \mathrm{C} / 32 \mathrm{~h}+900^{\circ} \mathrm{C} / 16 \mathrm{~h}(\mathrm{bd}=$ below detection limit).

\begin{tabular}{lllll}
\hline Sample & D1 $(\mathrm{meV})$ & D5 $(\mathrm{meV})$ & D2 $(\mathrm{meV})$ & B $^{\text {TO }}(\mathrm{meV})$ \\
\hline B14 & bd & bd & bd & 1086.9 \\
B14-A2 & 806 & 844 & 875 & 1088.0 \\
B12 & 823.5 & - & 876.5 & 1082.5 \\
B12-A2 & 811.3 & 847 & 875.5 & 1087.8 \\
B3 & 819 & - & - & 1059.6 \\
B3-A1 & 820 & - & - & 1056.0 \\
B3-A2 & $\sim 850$ & - & - & 1053.0 \\
B6 & 825 & - & - & 1043.5 \\
B6-A1 & 825 & - & - & 1055.0 \\
\hline
\end{tabular}

Complementary FTIR and TEM analysis has also been performed in order to facilitate the interpretation of the PL results. In the case of heavily doped silicon, problems arise due to the high free carrier absorption in the mid-IR region, i.e., around the $1106 \mathrm{~cm}^{-1}$ peak position of $\mathrm{O}_{\mathrm{i}}$ at $300 \mathrm{~K}$. In order to solve these, a method has been developed which relies on a special procedure of thinning of the samples, down to a thickness in the range 10-30 $\mu \mathrm{m}$. It is important to maintain the original material properties, which precludes heating the specimens, and to achieve a stress-free state [4]. The sensitivity of the method is further enhanced by performing measurements of the $1136.3 \mathrm{~cm}^{-1}$ absorption peak of $\mathrm{O}_{\mathrm{i}}$ at $6 \mathrm{~K}$, using an optimized conversion factor reported in [5].

\section{Results}

The first set of experiments was performed with the $3 \mu \mathrm{m}$ epilayer on top. Removing the epilayer by polishing $40 \mu \mathrm{m}$ off and etching did not markedly affect the PL spectra, except for the $\mathrm{B}^{\text {TO }} 1092 \mathrm{meV}$ line, which disappears from the spectrum for some of the polished $\mathrm{p}^{+}$ samples. This indicates that the $1092 \mathrm{meV}$ line originates from the lightly doped epilayer, while in the $\mathrm{p}^{+}$material, the $\mathrm{B}^{T O}$ line is shifted towards lower energies, as indicated in table 2 . As can be seen there, the shift increases for increasing doping density. At the same time, a broadening of the lines occurs, which can be expected from the band-gap narrowing, occurring at higher doping levels [10-12].

Figure 1 focuses on the energy region below $1 \mathrm{eV}$, where the features related to oxygen precipitates and/or dislocations are expected. It corresponds to the $68 \mathrm{~m} \Omega \mathrm{cm}$ material before and after annealing A2 (see table 1). As can be seen, before HT, weak bands already exist and are tentatively assigned to the D1 and D2 lines. However, the corresponding peak position reported in table 2 is clearly higher than $807 \mathrm{meV}$ for the D1 dislocation line and close to the expected value of $874 \mathrm{meV}$ for D2. According to the interpretation put forward by Pizzini et al [8,9] and following upon an original suggestion by Tajima et al [13], this points to the presence of oxygen precipitates in the B12 starting material. Furthermore, the high energy of the $\mathrm{D} 1$ line suggests an early stage of precipitation, leading to small $\mathrm{SiO}_{x}$ particles. In the $200 \mathrm{~m} \Omega \mathrm{cm}$ starting material B14, no PL lines above the detection limit of the technique were observed in the same spectral region (table 2).

Using the two-step anneal A2 results in the development of clear D1 and D2 lines in figures 1 and 2. While the D2 line remains at the same position, D1 has shifted close to its saturation value around $807 \mathrm{meV}$ [8]. This indicates the injection of silicon interstitials in 


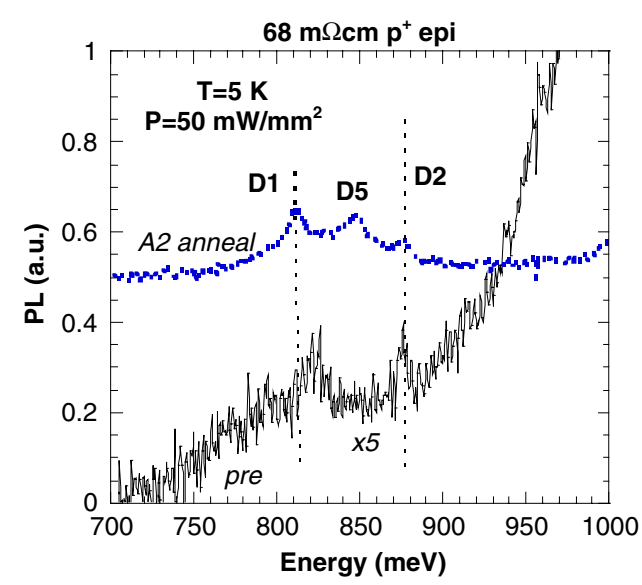

Figure 1. The PL spectrum of a $68 \mathrm{~m} \Omega \mathrm{cm} \mathrm{p}^{+}$sample before and after a two-step HT. The PL spectrum corresponding to the starting material has been multiplied by a factor of 5 .

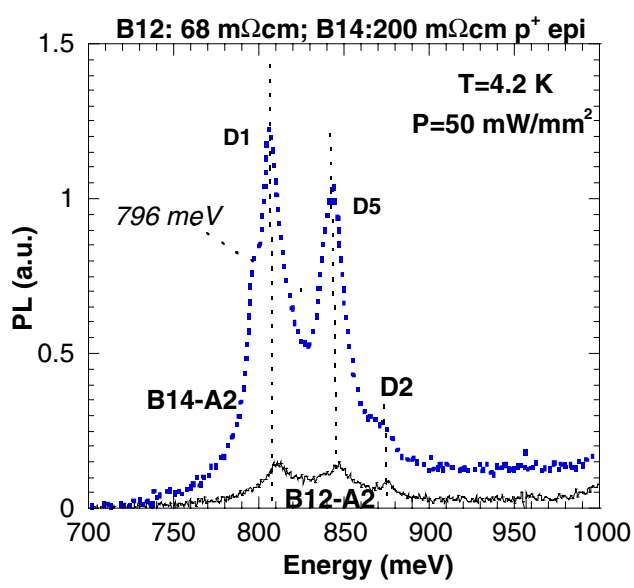

Figure 2. Comparison of the PL spectra for a 68 and a $200 \mathrm{~m} \Omega \mathrm{cm} \mathrm{p}^{+}$sample after a two-step HT.

the lattice upon proceeding with oxygen precipitation, in order to relax the strain around the growing precipitate. Eventually, when the stress becomes high enough, dislocation loops can be punched out. In fact, weak features around 958 and $1000.8 \mathrm{meV}$ in the spectrum of the two-step-annealed $200 \mathrm{~m} \Omega \mathrm{cm}$ sample could well correspond to the D3 and D4 dislocation lines. They are below the detection limit in B12.

In addition to D1 and D2, a peak around $845 \mathrm{meV}$ labelled D5 is also discerned after annealing in figures 1 and 2. A similar feature has been reported in Au-doped [14] and Er-doped silicon [8]. It has tentatively been ascribed to metal atoms (Me) captured by oxygen (precipitate), leading to $\mathrm{Me}-\mathrm{O}$ optically active bonds. It should also be recalled that $\mathrm{p}^{+}$material is very effective in gettering transition metals such as Fe, where they can be bound to oxygen precipitates during the HT.

Finally, a shoulder is clearly evident on the low-energy flank of the D1 line of the annealed $200 \mathrm{~m} \Omega \mathrm{cm}$ material. It could correspond to the D1a line at $802 \mathrm{eV}$ of [9].

Figures 3(a) and (b) exhibit the dependence of the PL on the excitation power at $T=6.8 \mathrm{~K}$ and on the temperature for $P=10 \mathrm{~mW} \mathrm{~cm}^{-2}$, for the annealed $200 \mathrm{~m} \Omega \mathrm{cm}$ material B14. The 

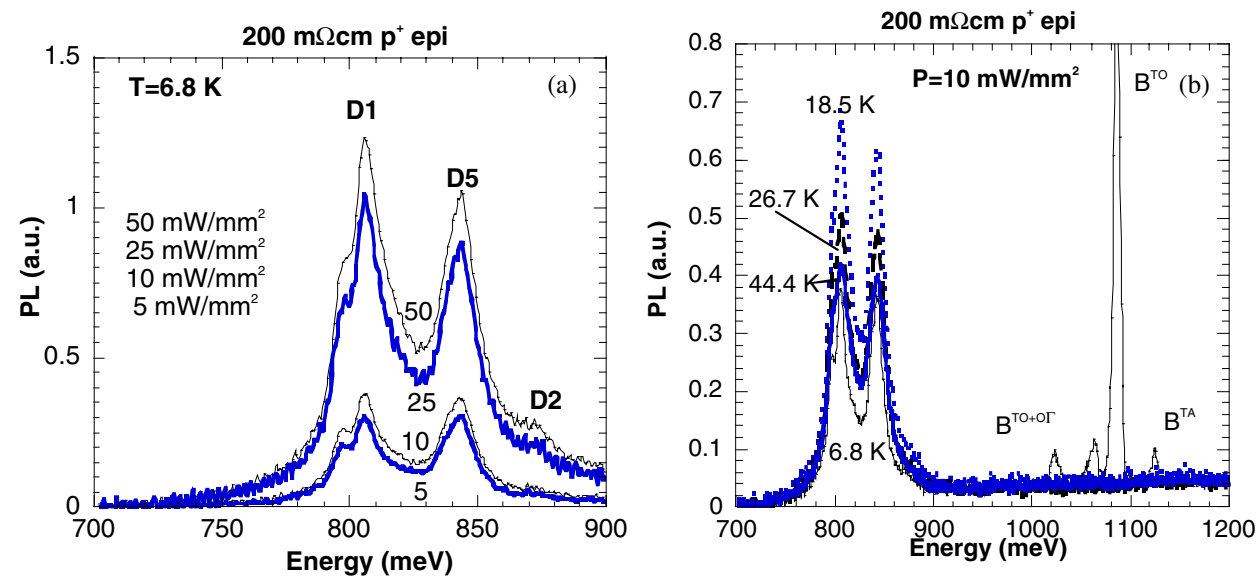

Figure 3. (a) PL spectra for different excitation power densities $P$ and (b) at $P=50 \mathrm{~mW} \mathrm{~mm}^{-2}$ for different temperatures, for the annealed $200 \mathrm{~m} \Omega \mathrm{cm} \mathrm{p}^{+}$material.

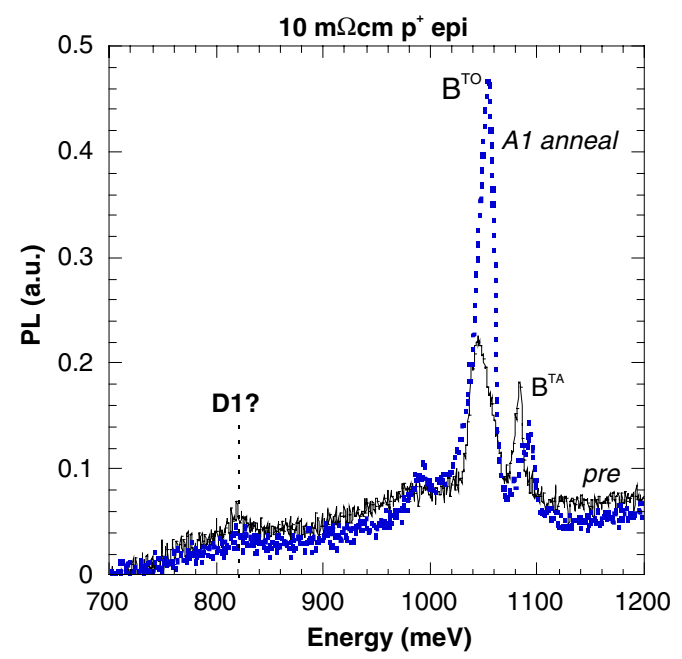

Figure 4. The PL at $T=5.5 \mathrm{~K}$ and $P=50 \mathrm{~mW} \mathrm{~mm}^{-2}$ for the $10 \mathrm{~m} \Omega \mathrm{cm}$ material before (full curve) and after (dotted curve) a $700^{\circ} \mathrm{C}$ anneal for $24 \mathrm{~h}$.

796 meV shoulder shows different behaviour with excitation power and with temperature. It becomes less pronounced with respect to the $\mathrm{D} 1$ peak for higher $T$ and/or $P$. It is also clear that the D1, D5 and D2 luminescence is retained at much higher temperatures than the B-related excitonic PL. One special feature is that the $6.8 \mathrm{~K}$ spectrum has a lower intensity than for the higher temperatures, which is rather unexpected from the literature [15]. At the moment, no explanation is available for this phenomenon.

For the 10 and $19 \mathrm{~m} \Omega \mathrm{cm}$ materials, the following results have been obtained. As mentioned above, no oxygen precipitation was found after the $700^{\circ} \mathrm{C}$ treatment just by FTIR investigation of the thinned samples. This is also confirmed by the PL spectra of figure 4 . The peak at $\sim 825 \mathrm{meV}$ is hardly affected by the $700{ }^{\circ} \mathrm{C}$ anneal and no evidence of a D2 or D5 line is found. It was, therefore, decided to prepare a second set of samples receiving the twostep anneal A2. The corresponding PL spectrum for the $19 \mathrm{~m} \Omega \mathrm{cm}$ material is represented in 


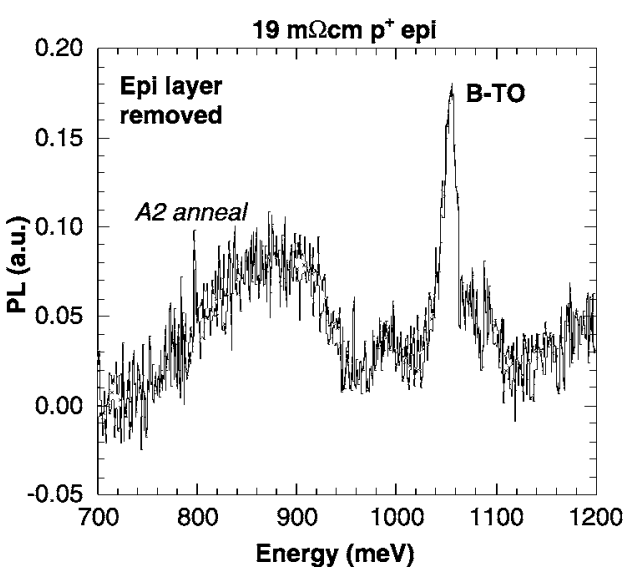

Figure 5. The PL at $T=6 \mathrm{~K}$ and $P=50 \mathrm{~mW} \mathrm{~mm}^{-2}$ for a $19 \mathrm{~m} \Omega \mathrm{cm}$ material after annealing A2, consisting of $32 \mathrm{~h}$ at $700^{\circ} \mathrm{C}$ and $16 \mathrm{~h}$ at $900^{\circ} \mathrm{C}$ under an $\mathrm{Ar}$ flow.

Table 3. Initial interstitial oxygen concentration determined from the height of the $1136 \mathrm{~cm}^{-1}$ local vibrational mode using the IOC-88 standard [17]. The samples were first thinned and polished to an appropriate thickness $[4,18]$. The presence and type of oxygen precipitates after a two-step annealing were measured using FTIR for $10^{19} \mathrm{~cm}^{-2} 2 \mathrm{MeV}$ electron-irradiated samples [4] using the analysis method of [6].

\begin{tabular}{llll}
\hline Sample & {$\left[\mathrm{O}_{\mathrm{i}}\right]\left(10^{17} \mathrm{~cm}^{-3}\right)$} & $\Delta\left[\mathrm{O}_{\mathrm{i}}\right]\left(10^{17} \mathrm{~cm}^{-3}\right)$ & Precipitate bands \\
\hline $\mathrm{B} 14$ & $8.2 \pm 0.5$ & 7.3 & Platelike + polyhedral \\
$\mathrm{B} 12$ & $8.0 \pm 0.5$ & 6.9 & Platelike + polyhedral \\
$\mathrm{B} 3$ & $6.8 \pm 0.8$ & 5.2 & Platelike \\
B6 & $9.2 \pm 1.2$ & 9.1 & Platelike \\
\hline
\end{tabular}

figure 5; it shows a broad feature in the $800-900 \mathrm{meV}$ region. This is clearly different to the 820 meV D1 line found in the starting material. As will be shown below, there is strong additional evidence of oxygen precipitation after the two-step anneal for all $\mathrm{p}^{+}$substrates studied.

\section{Discussion}

From the foregoing, some conclusions can be drawn regarding the PL of heavily doped $\mathrm{p}^{+}$ silicon subjected to an oxygen precipitation treatment. First, in the energy range of interest PL lines can already be found for the starting material, which could correspond to the D1-D2 emission bands in oxygen-precipitated $\mathrm{Cz}$ silicon. These lines grow after a two-step anneal in B12 and B14, where the D1 line shifts to a lower position-in line with the observations of $[8,9]$ - while D2 remains at approximately the same energy. In addition, some new peaks at $\sim 845$ and $796 \mathrm{meV}$ may develop for the 'lightly' doped samples B12 and B14 studied here.

In order to interpret the data more clearly, the PL results of table 2 are compared with the results revealed by the FTIR analysis and the findings summarized in table 3. More details will be published elsewhere [16]. There exists a distinction between the B12-B14 material on the one hand and the B3-B6 substrates on the other. While the former show a mixture of platelike and octahedral precipitates in the absorption spectrum of figure 6(a), only platelike precipitates are found for the 10 and $19 \mathrm{~m} \Omega \mathrm{cm}$ material (figure 6(b)). This is confirmed by the TEM results for B12 of figure 7. TEM also reveals the presence of bulk stacking faults (SFs) in all samples. 

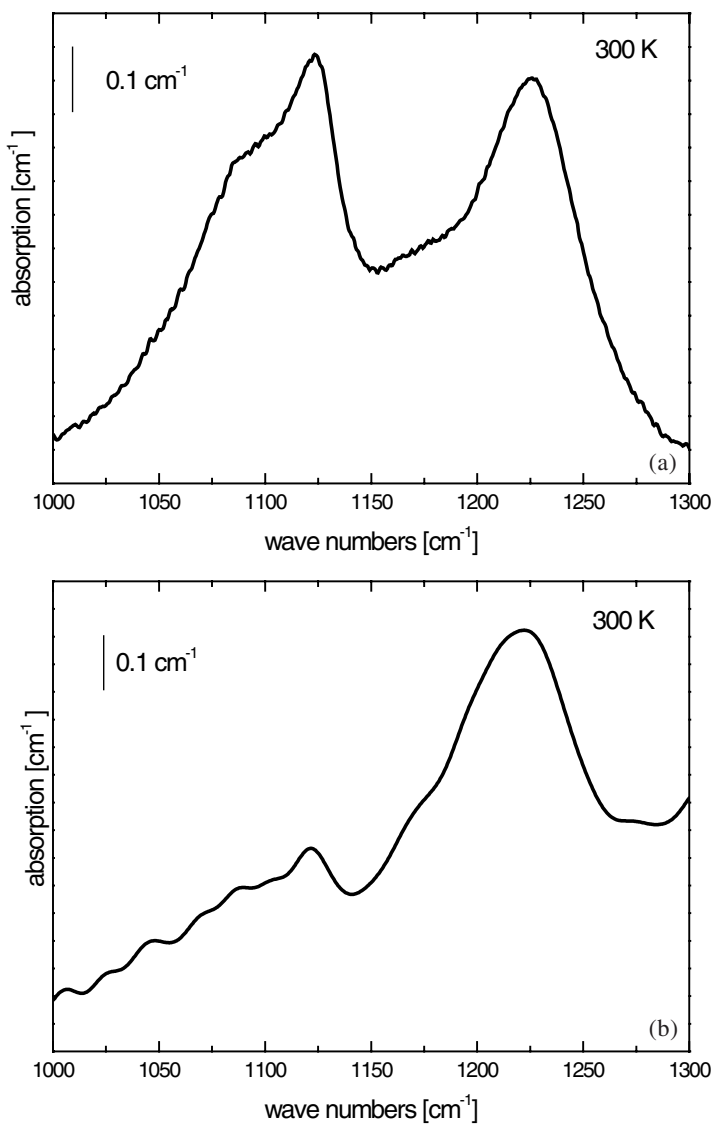

Figure 6. (a) The absorption spectrum due to the precipitates for the two-step-annealed $200 \mathrm{~m} \Omega \mathrm{cm}$ sample. The double resonance stems from polyhedral $\left(1110-1120 \mathrm{~cm}^{-1}\right)$ and platelet precipitates (1225 $\mathrm{cm}^{-1}$ ) [6]. (b) The absorption spectrum due to the precipitates for the two-step-annealed $19 \mathrm{~m} \Omega \mathrm{cm}$ sample. The absorption band with a maximum around $1225 \mathrm{~cm}^{-1}$ corresponds to platelet precipitates.

It remains to explain the impact of the B concentration on the oxygen precipitation behaviour. In this context, it should be noted that the presence of a high boron concentration has a strong effect on the strain relaxation around an oxide precipitate, which results in a change in the precipitate morphology from platelike to polyhedral and the emission of silicon interstitials [3]. It is, therefore, expected that precipitate strain relaxation by interstitial injection in the matrix will happen earlier for the less heavily doped material B12-B14 compared with B3-B6. This probably explains the nature of the PL spectra reported here: for the 68 and $200 \mathrm{~m} \Omega \mathrm{cm}$ material, D1, D2 and D5 lines develop, whereby the D1 line shifts to the energy which is thought to correspond to dislocations/interstitials. One curious fact calling for further investigations is the observation of SFs in the heavily doped B3-B6 material by TEM, without any clear evidence of the D1-D2 lines developing after the two-step anneal.

\section{Conclusions}

It has been shown that PL is a promising technique for the study of oxygen precipitation in heavily doped $\mathrm{Cz}$ silicon, which requires no special sample preparation, i.e., no high-fluence 


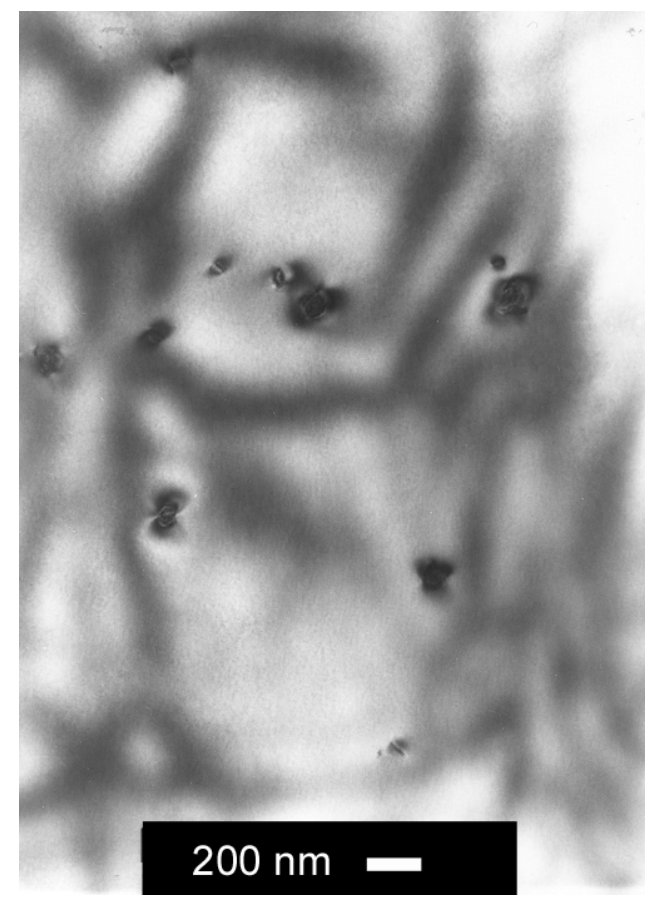

Figure 7. A plan-view TEM image of the two-step-annealed $68 \mathrm{~m} \Omega \mathrm{cm} \mathrm{p}^{+}$material, showing the presence of platelet oxygen precipitates.

irradiation. From the observation of D1-D2 lines in some of the starting material, without any corresponding evidence for precipitation found by TEM or FTIR, it may be concluded that the PL technique is probably more sensitive than the others. A detailed correlation study between the three techniques should result in a more quantitative analysis of oxygen precipitation in heavily doped silicon by means of PL.

\section{Acknowledgments}

Part of this work was performed within the framework of the European Network on Defect Engineering in Advanced Semiconductor Devices (ENDEASD_ERB 4061 PL 97-0645). Partial financial support was provided by the FWO under project No G005197N. Discussions with J Vanhellemont are highly appreciated. Wacker Siltronic is acknowledged for providing the epitaxial material and relevant data. Finally, we wish to thank the Institut für Schichten und Grenzflächen, Forschungszentrum Jülich, for allowing us to use their PL set-up.

\section{References}

[1] Sueoka K, Akatsuka M, Ono T, Asayama E, Koike Y, Adachi N, Sadamitsu S and Katahama H 2000 Proc. High Purity Silicon VI (The Electrochem. Soc. Proc. vol PV 2000-17) ed C L Claeys, P Rai-Choudhury, M Watanabe and P Stallhofer (Pennington, NJ: The Electrochemical Society) pp 164-79

[2] Kubota H, Nagano H, Sugamoto J, Matsushita H, Momose M, Nitta S, Samata S and Tsuchiya N 2000 Proc. High Purity Silicon VI (The Electrochem. Soc. Proc. vol PV 2000-17) ed C L Claeys, P Rai-Choudhury, M Watanabe, P Stallhofer and H J Dawson (Pennington, NJ: The Electrochemical Society) pp 634-45

[3] Ono T, Asayama E, Horie H, Hourai M, Sueoka K, Tsuya H and Rozgonyi G A 1999 J. Electrochem. Soc. 146 2239-44 
[4] De Gryse O, Clauws P, Rossou L, Van Landuyt J, Vanhellemont J and Mondelaers W 1998 Proc. High Purity Silicon V(The Electrochem. Soc. Proc. vol 98-13) ed C L Claeys, P Rai-Choudhury, M Watanabe, P Stallhofer and H J Dawson (Pennington, NJ: The Electrochemical Society) pp 398-409

[5] De Gryse O and Clauws P 2000 J. Appl. Phys. 87 3294-300

[6] De Gryse O, Clauws P, Van Landuyt J, Lebedev O, Claeys C, Simoen E and Vanhellemont J 2002 J. Appl. Phys. $912493-8$

[7] Drozdov N A, Patrin A A and Tkachev V D 1977 Phys. Status Solidi b 83 K137-9

[8] Pizzini S, Acciarri M, Leoni E and LeDonne A 2000 Phys. Status Solidi b 222 141-50

[9] Binetti S, Pizzini S, Leoni E, Somaschini R, Castaldini A and Cavallini A 2002 Solid State Phenom. 82-84 $75-80$

[10] Parsons R R 1979 Solid State Commun. $29763-6$

[11] Wagner J 1984 Phys. Rev. B 29 2002-9

[12] Wagner J, Appel W and Warth M 1986 J. Appl. Phys. 59 1305-8

[13] Tajima M, Tokita M and Warashina M 1995 Mater. Sci. Forum 196-201 1749-54

[14] Higgs V, Goulding M, Brinklow A and Kightley P 1992 Appl. Phys. Lett. 60 1369-71

[15] Suezawa M, Sasaki Y and Sumino K 1983 Phys. Status Solidi a 79 173-81

[16] De Gryse O, Clauws P, Vanhellemont J, Lebedev O, Van Landuyt J, Simoen E and Claeys C 2002 Proc. High Purity Silicon VII (The Electrochem. Soc. Proc.) ed C L Claeys, P Rai-Choudhury, M Watanabe and P Stallhofer (Pennington, NJ: The Electrochemical Society) at press

[17] Baghdadi A, Bullis W, Croarkin M, Li Y-Z, Scace R, Series R, Stallhofer P and Watanabe M 1989 J. Electrochem. Soc. 136 2015-24

[18] De Gryse O, Clauws P, Rossou L, Van Landuyt J, Vanhellemont J and Mondelaers W 1999 Rev. Sci. Instrum. 70 3661-3 